Article

\title{
Spray-on PEDOT:PSS and P3HT:PCBM Thin Films for Polymer Solar Cells
}

\section{Morteza Eslamian $^{\dagger} *$ and Joshua E. Newton}

School of Engineering and Computing Sciences, Texas A\&M University-Corpus Christi, Corpus Christi, TX 78412, USA

$\dagger$ Present address: University of Michigan-Shanghai Jiao Tong University Joint Institute, Shanghai 200240, China.

* Author to whom correspondence should be addressed; E-Mails: morteza.eslamian@ tamucc.edu; morteza.eslamian@sjtu.edu.cn; Tel.: +86-21-3420-7249; Fax: +86-21-3420-6525.

Received: 6 December 2013; in revised form: 31 December 2013 / Accepted: 8 January 2014 /

Published: 21 January 2014

\begin{abstract}
PEDOT:PSS electron-blocking layer, and PEDOT:PSS + P3HT:PCBM stacked layers are fabricated by ultrasonic atomization and characterized by scanning electron microscopy (SEM) and optical profilometry. The measured thicknesses based on SEM and optical profilometry are quite different, indicating the incapability of measurement techniques for non-uniform thin films. The thickness measurements are compared against theoretical estimations and a qualitative agreement is observed. Results indicate that using a multiple pass fabrication strategy results in a more uniform thin film. It was also found that the film characteristics are a strong function of solution concentration and spraying passes, and a weak function of substrate speed. Film thickness increases with solution concentration but despite the prediction of theory, the increase is not linear, indicating a change in the film porosity and density, which can affect physical and opto-electrical properties. Overall, while spray coating is a viable fabrication process for a wide range of solar cells, film characteristics can be easily altered by a change in process parameters.
\end{abstract}

Keywords: solution processed solar cells; polymer solar cells; spray coating; thin film characterization; spray-on solar cells 


\section{Introduction}

Crystalline silicon solar cells are the first generation of solar cells fabricated and they are currently the major player in the field, as far as commercialization and current sales are concerned. Solar cells of the second generation, such as copper indium gallium selenide (CIGS) and cadmium telluride (CdTe) need less material, but are still costly and need special equipment and energy consuming processes such as vapor deposition for their production. The third generation of solar cells (polymeric, organic, quantum dot and dye-sensitized solar cells) has emerged in the last decade or so, with the hope to allow for the fabrication of large area panels using less-complex processes and less-expensive materials and equipment, but still suffer from low efficiencies, stability, and durability. The third generation solar cells, instead of expensive semiconductors, usually employ solution-processed materials such as polymers, nanoparticles and additives which make them easier to manufacture using cheap methods and processes [1].

The current methods employed for fabricating solution processed solar cells include, but are not limited to, spin-coating, electrophoresis, knife over edge (doctor blading), screen printing, slot-die, coating, gravure printing, ink jet printing and spray coating [1-3]. In these methods, the precursor solution is transferred onto a substrate to make a thin film. Wengeler et al. [3] compares the large area coating methods for polymer solar cells including knife coating, slot-die coating, and spray coating with laboratory spin coating method. As expected, the results indicated that the coating method itself has an impact on the film morphology and opto-electrical properties. It is believed that spray coating has a high potential for making fast and low-cost spray-on solar cells. However, since the spray coating process is poorly understood and the results are inconclusive, the objective of this work is to gain more insight into the characteristics of spray-on solar cell layers. In particular, the effect of substrate speed, solution concentration and number of spray passes will be studied on the formation of spray-on thin films used in polymer solar cells.

The spray-coating method permits fast and low-cost fabrication of large area solar cells on flexible substrates using a roll-to-roll (R2R) approach. To fabricate such thin films by spray deposition, proper coating blends, such as polymers, are suspended or dissolved in a proper solvent or carrier; the mixture or solution is then sprayed onto a substrate to form a thin film of the order of 10-100 nm or so. Droplet and spray technologies, such as ink-jet printing, cold spray deposition, spray pyrolysis and thermal spray coating may serve to fabricate various layers of solar cells. Ink-jet printing is a high precision and high resolution technique, but compared to spray coating it is a slower process. It appears that ink-jet printing is more suitable for the fabrication of lines and grids such as electrodes [4] rather than the entire surface area of the active layer of a solar cell.

One reason that spray technology is not well accepted as a viable fabrication method in the solar industry is perhaps due to the high purity, uniformity and device performance expectations. Spray coating is a multi-step method, comprising independent steps such as atomization of a liquid solution or mixture, droplet flight and evaporation and droplet impact on the substrate, droplet spreading, drying and adhesion of the solid content to one another and to the substrate to form a thin film. To obtain a high quality and acceptable spray-on layer, all of these processes have to be well understood and controlled [5]. 
An important class of thin film solar cells that can be fabricated almost entirely via spray technology is the polymer solar cells. In a polymer solar cell, an active layer is sandwiched between two collecting electrodes. One of the electrodes must be transparent to allow the light transmission to the active layer. Currently indium tin oxide (ITO) is the widely used transparent electrode. For the second electrode, silver, aluminum and other metals that have the right work function are used [1]. The active layer is comprised of an electron donor and an electron acceptor. The common and currently used approach is to blend the donor and acceptor materials in a solution, transfer the solution to the substrate, and let the solvent evaporate leaving behind a thin film.

Once photons strike on the solar cell and reach the active layer, an exciton (similar to an electron-hole pair in semiconductors) forms. The exciton diffuses to the boundaries of the donor-acceptor blend where it dissociates to an electron and a hole. The electrons and holes then transfer to the opposite electrodes. To minimize charge recombination, intermediate or buffers layers may be used between the electrodes and the active layer to block the electron or hole transfer in the wrong direction. Some examples of hole transfer buffer layers include PEDOT:PSS or poly(3,4-ethylenedioxythiophene) poly(styrenesulfonate), $\mathrm{V}_{2} \mathrm{O}_{5}$ and $\mathrm{MoO}_{3}$. Electron transfer buffer layers are in the form of metal oxides [6].

Blend of poly(3-hexylthiophene) (P3HT), a polymer, and [6,6]-phenyl C61-butyric acid methylester (PCBM), a fullerene derivate based donor-acceptor copolymer, is one of the widely used organic solar cell materials for photon-electron conversion. Organic polymers such as P3HT:PCBM blends have wider band gaps than natural semiconductors. Thus they have an efficient absorption at near UV part [6]. Figure 1 shows a bulk heterojunction polymer photovoltaic cell and the exciton dissociation at the donor-acceptor interface. The approximate thickness of the layers is also given [7].

Figure 1. Layer structure of the polymer solar cell with approximate film thicknesses. Electron donor (P3HT) and acceptor (PCBM) are blended together to maximize the interface where exciton dissociation into electrons and holes takes place [7]. P3HT: poly(3-hexylthiophene); PCBM: [6,6]-phenyl C61-butyric acid methylester; PEDOT:PSS: poly(3,4-ethylenedioxythiophene) poly(styrenesulfonate); ITO: Indium Tin Oxide.

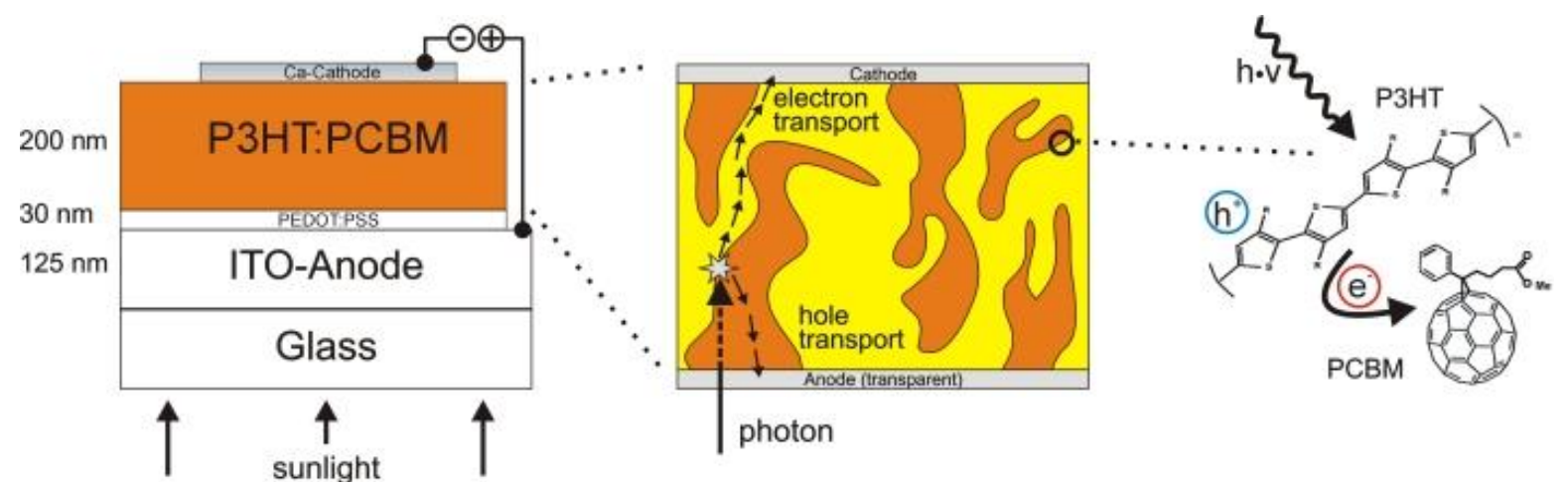

PEDOT:PSS layer, which is an electron blocking layer and also an anode in some configurations, has been fabricated by spray coating and studied rather well [8-11]. In an attempt to reduce or eliminate the defects such as pinholes and non-uniformities, Lee et al. [12,13] studied the effect of annealing and also the effect of using various solvents for spray coating of P3HT:PCBM layer on PEDOT:PSS. The sprayer is a gas-assist nozzle (air brush). It was found that additional spraying of ortho-dichlorobenzene (DCB) 
solvent after the conventional spray coating process of P3HT:PCBM improves all physical, optical and electronic characteristics of the film.

Lewis et al. [14] produced all layers of an inverted polymer solar cell by spray coating, using an airbrush. The cell consists of four layers including ITO- $\mathrm{Cs}_{2} \mathrm{CO}_{3}-(\mathrm{P} 3 \mathrm{HT}: \mathrm{PCBM})-$ modified PEDPT:PSS, formed on a glass substrate, where the semi-transparent PEDPT:PSS plays the role of the anode. The encapsulated solar array showed more than $30 \%$ transmission in the visible-near IR range. Girotto et al. [15-17] used ultrasonic atomization to fabricate PEDOT:PSS and P3HT:PCBM layers. The current density and absorbance of spray coated devices were comparable to spin-coated devices. In another study using ultrasonic atomization [18], the utility of concurrent spray coating was investigated. In this technique two independent solutions were coaxially pumped to the ultrasonic nozzle tip of the spray coater, each consisting of one of the two respective solutions with negligible mixing. By controlling the drying parameters, the two mixtures blend on the substrate to form a desired layer. Chen et al. [19] used a similar approach in which P3HT and PCBM are sprayed through two nozzles. This was done to control the domain formation and phase separation in the active layer. Peh et al. [20] demonstrated that through using PEDOT:PSS highly diluted with low surface tension solvents such as isopropanol alcohol and butanol, a relatively uniform and thin layer can be achieved on P3HT:PCBM by spray coating (using an airbrush) due to improved wetting on P3HT:PCBM. Lee et al. [21] have recently investigated some of the characteristics of the spray-on films such as optical properties as well as the optimum ratio of $\mathrm{P} 3 \mathrm{HT}$ and $\mathrm{PCBM}$ in a polymer solar cell in order to maximize the cell efficiency. A review of potentials, challenges and research directions on spray-on solar cells may be found in Ref. [22].

\section{Experimental Section}

The ITO-coated glass substrates used here have dimensions of $75 \mathrm{~mm}$ by $25 \mathrm{~mm}$ and a thickness of $1 \mathrm{~mm}$. They were cleaned using an isopropyl alcohol bath in an ultrasonic cleaner for $10 \mathrm{~min}$ at $69{ }^{\circ} \mathrm{C}$. Then rinsed in de-ionized water and allowed to air dry for approximately $30 \mathrm{~min}$. The as-received $13 \mathrm{~g} / \mathrm{L}$ PEDOT:PSS (Sigma-Aldrich, Saint Louis, MO, USA) mixture was diluted using de-ionized water to solutions of $1 \mathrm{~g} / \mathrm{L}, 5 \mathrm{~g} / \mathrm{L}$, and $10 \mathrm{~g} / \mathrm{L}$. An additional $5 \%$ per solution of Ethanolamene (Sigma-Aldrich, Saint Louis, MO, USA) was added to each mixture. The PCBM and P3HT powders were mixed in ratio of 1:1 and dissolved in chlorobenzene (Sigma-Aldrich, Saint Louis, MO, USA). Solutions with concentrations of 1,5 and $10 \mathrm{~g} / \mathrm{L}$ were prepared.

The ExactaCoat spray coating machine (Sono-Tek, Milton, NY, USA) equipped with an ultrasonic atomization nozzle, syringe pump, automatic 3D traverse system, programming control software and hot plate was used to fabricate the samples [5]. The machine was programmed to achieve the desired number of passes, liquid flow rate and substrate-nozzle relative speed (in the experiments, the spray nozzle was moving and the substrate was stationary, but here the relative speed between the nozzle and the substrate is denoted as the substrate speed). The ITO-coated glass substrate was placed on the hot plate and allowed to sit for $1 \mathrm{~min}$ to let the surface moisture evaporates. The solution was then pumped and sprayed through a syringe pump and the ultrasonic nozzle for each respective parameter, while the nozzle was moving at a desired speed. After each solution was sprayed, the substrate was allowed to remain on the hot plate for an additional $1 \mathrm{~min}$ for removal of the residual moisture and annealing. The substrate was then removed and placed on a cooling rack and allowed to cool at room temperature. For 
the PCBM:P3HT solutions, the process was the same only the solution was sprayed on the pre-existing PEDOT:PSS layers.

The prepared samples were subjected to scanning electron microscopy (SEM) analysis and also optical profilometry for the measurement of the film thickness, thickness distribution, topography, etc. The make and model of the microscope is AMRAY 1830 SEM. For the SEM analysis, the center of each slide was used to obtain the surface images at two magnifications. The cross section was prepared by scoring the center of the slide with a diamond blade roller. An F-42 model optical profilometer (Filmetrics, San Diego, CA, USA) was used also for the optical surface analysis. The F-42 provides a mapping of the film thickness over selected areas. The selected area here is about $1.4 \mathrm{~mm}$ by $1.4 \mathrm{~mm}$ and the reported average thickness is the average thickness over that area.

In all experiments, the substrate temperature was kept at $150{ }^{\circ} \mathrm{C}$; the substrate distance from nozzle tip was $74 \mathrm{~mm}$; the liquid precursor flow rate was set at $10 \mathrm{~mL} / \mathrm{min}$, and the nozzle impact air pressure was set at 5 psi. These are some important process variables that are controlled by the ultrasonic machine and their variation can affect the film morphology but were kept constant in this work.

Total of 32 samples were fabricated at various conditions. Three solution concentrations (1, 5, and $10 \mathrm{~g} / \mathrm{L})$ and two substrate speeds $(0.3$ and $0.6 \mathrm{~m} / \mathrm{s})$, were used for each material and the spraying strategy was either single pass or two consecutive spray passes over each sample. Therefore, our results show the effect of concentration, substrate speed and the number of passes on the film thickness and topography. Figure 2 schematically shows the process of spray coating of PEODT:PSS and P3HT:PSS films on ITO-coated glass substrates.

Figure 2. Spray coating of (a) PEDOT:PSS and (b) P3HT:PCBM layers on ITO-coated glass substrates.

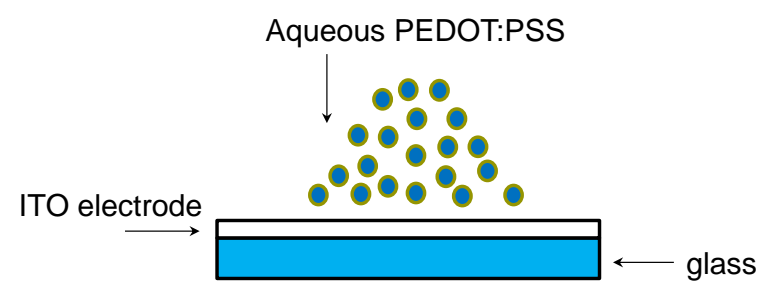

(a)

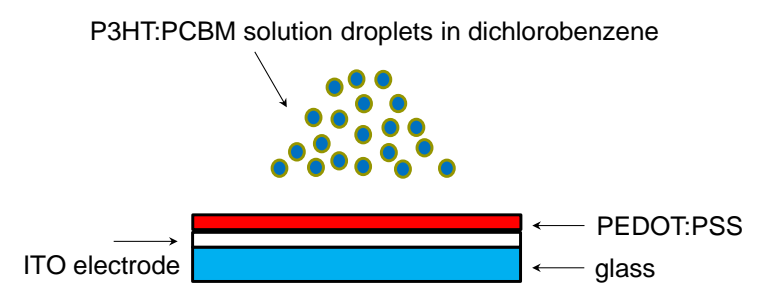

(b)

\section{Results and Discussion}

\subsection{Optical Profilometry}

Twelve samples coated with PEDOT:PSS were analyzed for film thickness distribution and average thickness, using an optical profilometer. Table 1 shows the fabrication conditions of these samples and the analysis results. The analysis result of sample 1 was found dubious and therefore eliminated from the table and excluded from the analysis and discussion. The standard deviation (SD) associated with each average thickness is quite large indicating a non-uniform film thickness distribution. The large SD associated with the measurements makes it difficult to draw specific conclusions. Nevertheless, one can clearly observe that the film thickness increases with an increase in the initial solution concentration. When the number of passes is doubled, one would expect the film thickness to become doubled as well. 
This can be seen for samples 5A and 6A, but not for other samples necessarily. Also, when the substrate speed is doubled while other parameters are kept constant, one would expect the film thickness to become half of the original thickness. The results do not support this indicating the complex dynamics of the coating process and non-uniformity of the films and perhaps the inadequacy of the optical interferometry for determining the thickness of non-uniform films. To further investigate this, we have analyzed the sample images to gain more insight into the deposition process (Figures 3 and 4).

Table 1. PEDOT:PSS film average thickness and standard deviation (SD) obtained by optical profilometry for various samples at given solution concentration, substrate speed and number of passes.

\begin{tabular}{cccccc}
\hline Sample ID & $\boldsymbol{c}_{\mathbf{0}}(\mathbf{g} / \mathbf{L})$ & $\boldsymbol{u}_{\boldsymbol{s u b}}(\mathbf{m} / \mathbf{s})$ & No. of Passes & Thickness $(\mathbf{n m})$ & SD $(\mathbf{n m})$ \\
\hline 2A & 1 & 0.3 & 2 & 16 & 53 \\
3A & 1 & 0.6 & 1 & 23 & 49 \\
4A & 1 & 0.6 & 2 & 42 & 57 \\
5A & 5 & 0.3 & 1 & 84 & 119 \\
6A & 5 & 0.3 & 2 & 165 & 67 \\
7A & 5 & 0.6 & 1 & 170 & 154 \\
8A & 5 & 0.6 & 2 & 165 & 56 \\
9A & 10 & 0.3 & 1 & 258 & 132 \\
10A & 10 & 0.3 & 2 & 200 & 111 \\
11A & 10 & 0.6 & 1 & 181 & 82 \\
12A & 10 & 0.6 & 2 & 175 & 95 \\
\hline
\end{tabular}

Figure 3. Effect of spray passes: Optical profilometry pictures and film thickness distribution of PEDOT:PSS spray coated on ITO-coated glass for (a) single spray pass (average film thickness $=23 \mathrm{~nm}$ ) and $(\mathbf{b})$ double spray pass (average film thickness $=42 \mathrm{~nm}$ ). Precursor concentration is $1 \mathrm{~g} / \mathrm{L}$ and substrate speed is $0.6 \mathrm{~m} / \mathrm{s}$. Each image is $1.4 \mathrm{~mm}$ by $1.4 \mathrm{~mm}$ and the color scale is in $\mathrm{nm}$.

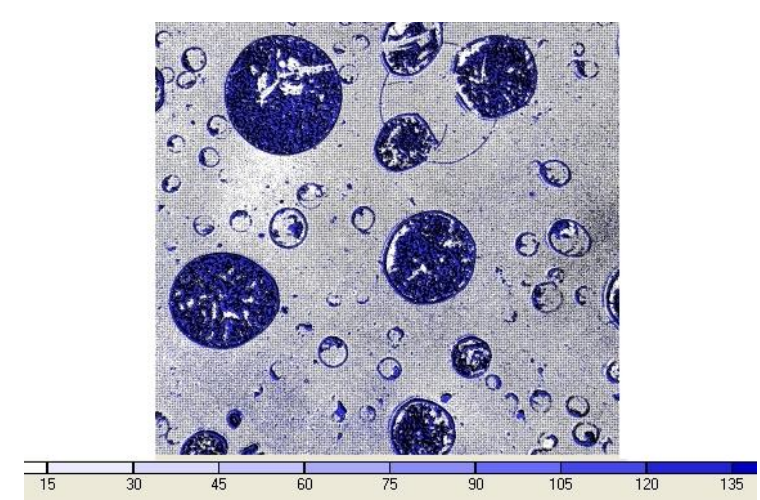

(a)

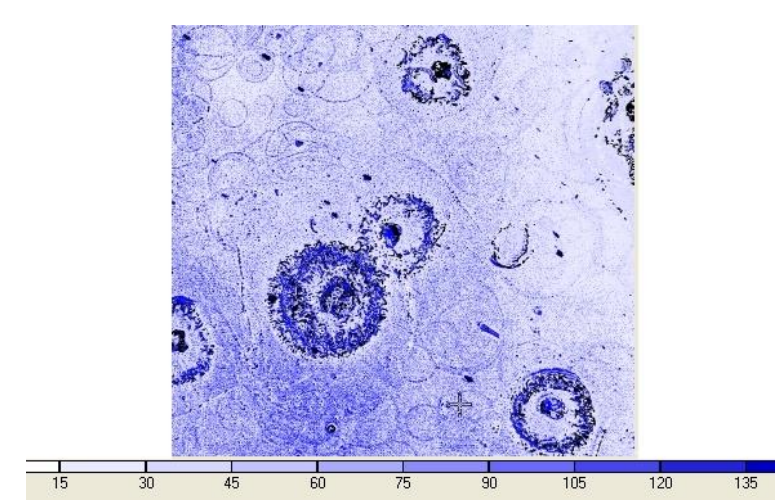

(b)

Figure 3 shows the effect of spray passes on the film morphology for (a) single spray pass and (b) double spray pass at constant precursor concentration $(1 \mathrm{~g} / \mathrm{L})$ and substrate speed of $0.6 \mathrm{~m} / \mathrm{s}$. The image size is $1.4 \mathrm{~mm}$ by $1.4 \mathrm{~mm}$ and therefore the large droplet splats or coins are greater than $100 \mu \mathrm{m}$. Prints of much smaller droplets and a thin layer film are also visible. For other cases studied here, i.e., other solution concentrations and substrate speeds, similar trends were observed. Comparison of Figure $3 \mathrm{a}, \mathrm{b}$ 
shows that increasing the number of passes results in the formation of a more uniform film. The ultrasonic generated spray is composed of droplets with average size of $48 \mu \mathrm{m}$. Some of the droplets that impact on the substrate may shatter and form smaller satellite droplets, as seen in the image. Both images show that the film is composed of two parts: one is a rather uniform layer of light blue which is about $15-30 \mathrm{~nm}$ and isolated droplets on the top. The coffee-ring effect is also clearly seen in smaller droplets [5], indicating that the solute has diffused to the edges of small droplets and solidified. This can be explained as follows: Once the first group of spray droplets hit the substrate, they spread, dry quickly and form a thin layer. Close to the end of the spraying time, some of the forthcoming droplets may dry individually. Also, since such droplets experience a lower temperature than the substrate temperature, the coffee-ring effect is observed. Coffee-ring effect occurs in slow evaporation processes. When the number of passes increases to two, fewer individual droplets are present and the film is more uniform. The positive effect of having more passes was observed in all cases (no shown here). Our results showed that as the precursor concentration increases the film becomes more uniform and the individual droplets disappear. Figure 4 shows a typical uniform film at $5 \mathrm{~g} / \mathrm{L}$ at two passes and substrate speed of $0.6 \mathrm{~m} / \mathrm{s}$.

Figure 4. A rather uniform film (sample 8A): Optical profilometry picture and film thickness distribution of PEDOT:PSS spray coated on ITO-coated glass for a double spray pass. Precursor concentration is $5 \mathrm{~g} / \mathrm{L}$ and substrate speed is $0.6 \mathrm{~m} / \mathrm{s}$. The color scale unit is in $\mathrm{nm}$.

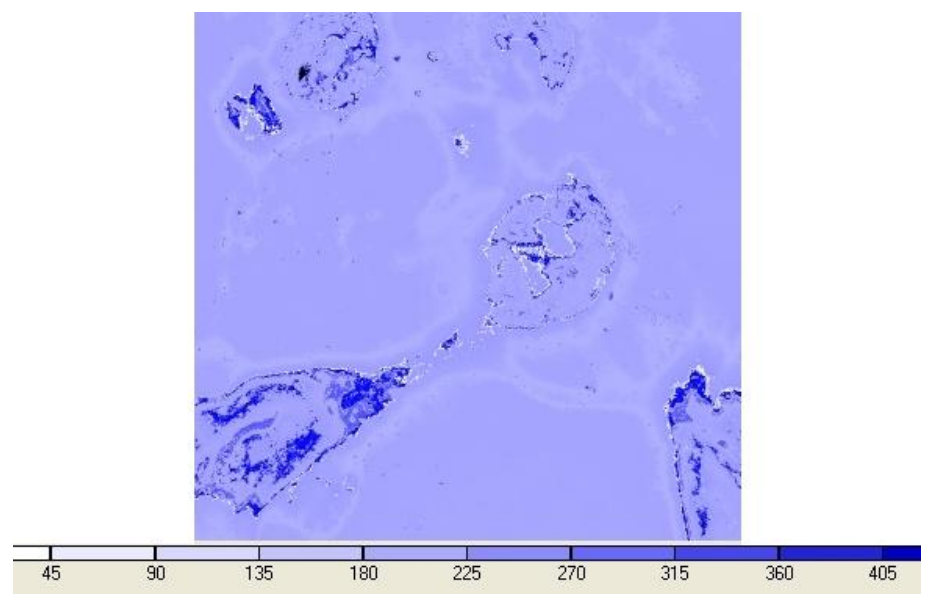

\subsection{SEM Analysis}

The optical profilometry images and measurements provided useful information and some physical insight. One of the findings was that the films are composed of two parts, one rather uniform layer underneath and several large droplet splats or coins on the top, where the latter is unfavorable. SEM images at two magnifications were taken for 24 spray coated samples by PEDOT:PSS and also PEDOT:PSS + P3HT:PCBM solutions.

In Figure 5 is shown the SEM images of PEDOT:PSS layers (left column) and PEDOT:PSS + P3HT:PCBT layers (right column) for three initial solution concentrations. In all cases, the substrate speed is $0.3 \mathrm{~m} / \mathrm{s}$, and the number of spray passes is two, i.e., two passes of PEDOT:PSS for the case of PEDOT:PSS single layer, and two passes of each solution for PEDOT:PSS + P3HT:PCBM stacked layers. At the lowest solution concentration, i.e., at $1 \mathrm{~g} / \mathrm{L}$, the PEDOT:PSS film is highly non-uniform and the trace of the droplets and the coffee ring effect can be seen. Given that the scale bar is $100 \mu \mathrm{m}$, 
dried splats as large as several hundreds of micrometers are observed. The average droplet size in the spray is $48 \mu \mathrm{m}$ and the presence of very large splats may be due to droplet collision and coalescence during the droplet flight and/or after impact. The most uniform films appear to have formed at $5 \mathrm{~g} / \mathrm{L}$ for both PEDOT:PSS and PEDOT:PSS + P3HT:PCBM layers. At the highest concentration, the PEDOT:PSS film is uniform, but after deposition of P3HT:PCBM layer, the surface morphology changes and it seems that the surface integrity and uniformity is somewhat altered or lost.

Figure 5. SEM images of the PEDOT:PSS layer (left column) and PEDOT:PSS + P3HT:PCBT layers (right column) for initial solution concentration of (a) $c_{0}=1 \mathrm{~g} / \mathrm{L}$, (b) $c_{0}=5 \mathrm{~g} / \mathrm{L}$, and (c) $c_{0}=10 \mathrm{~g} / \mathrm{L}$. In all cases, the substrate speed is $0.3 \mathrm{~m} / \mathrm{s}$, and the number of spray passes is two.
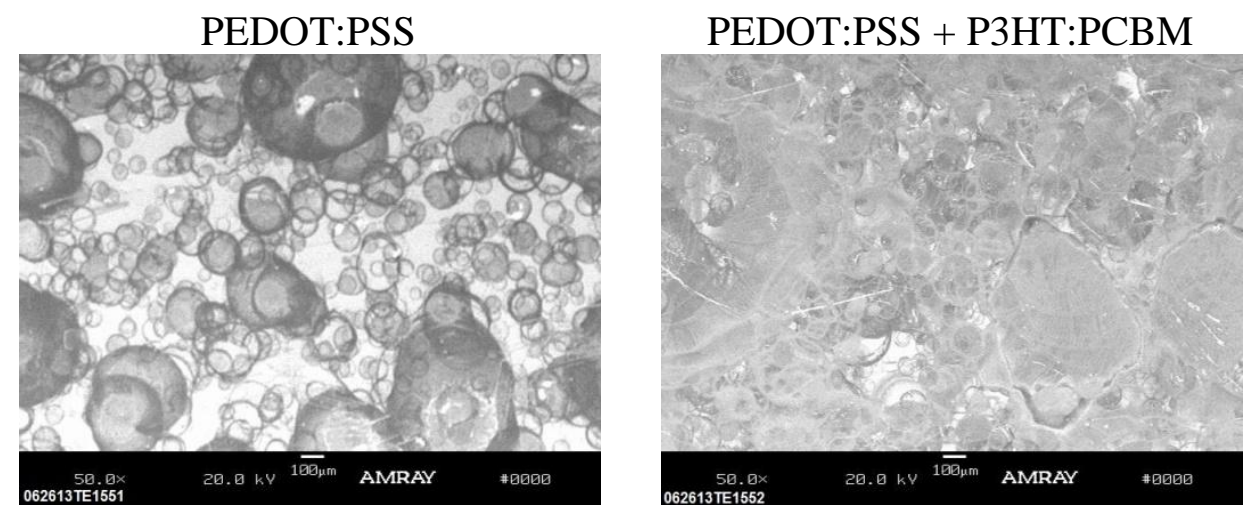

(a) $c_{0}=1 \mathrm{~g} / \mathrm{L}$

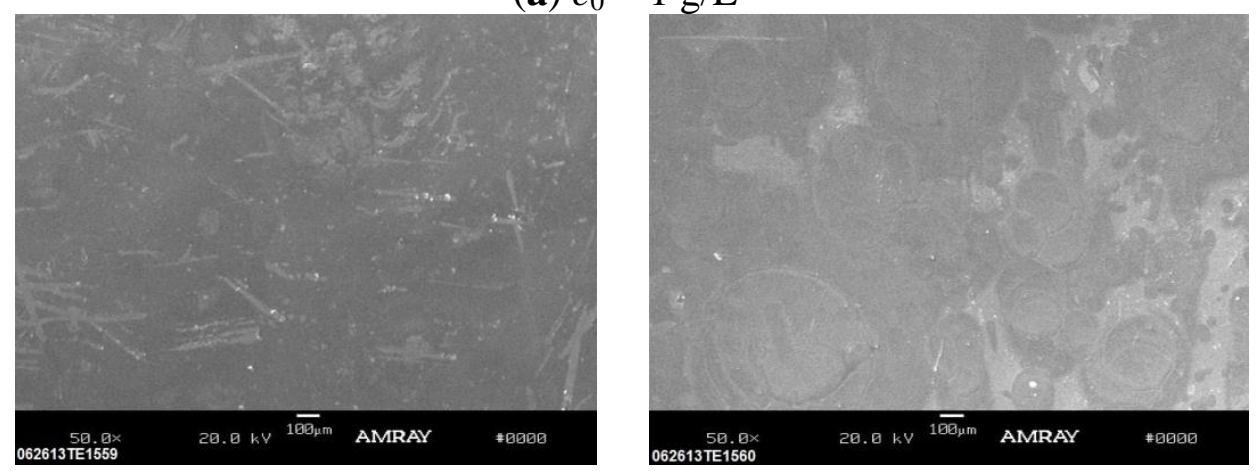

(b) $c_{0}=5 \mathrm{~g} / \mathrm{L}$

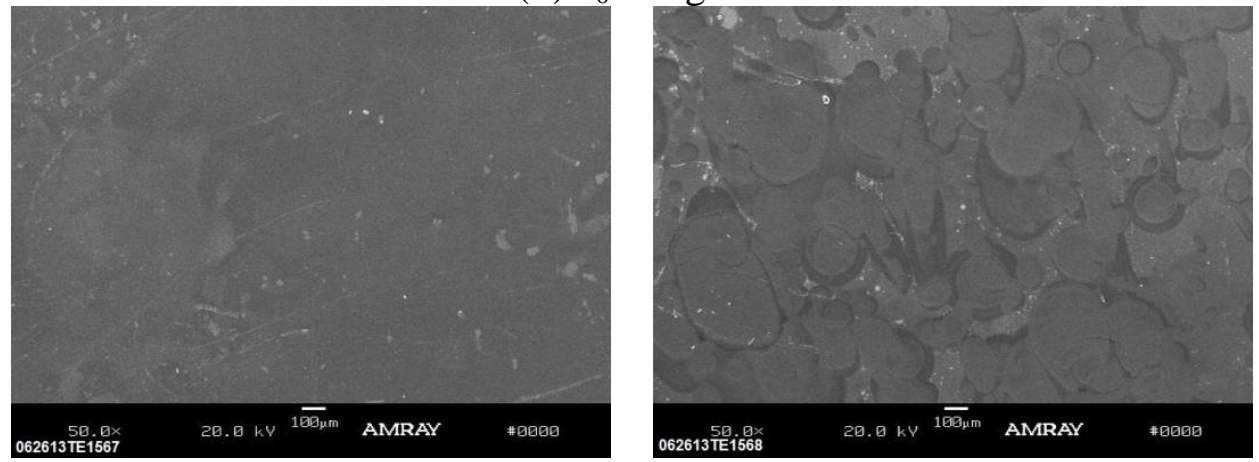

(c) $c_{0}=10 \mathrm{~g} / \mathrm{L}$ 
Figure 6 shows the effect of spray passes on the film uniformity and topography at $c_{0}=5 \mathrm{~g} / \mathrm{L}$ and $u_{s u b}=0.6 \mathrm{~m} / \mathrm{s}$. The right column shows that samples prepared in a double pass process have a more uniform surface area. Using multiple passes is beneficial as far as film uniformity and integrity is concerned, however, it results in a thick film that may not be desired in some applications. Also, using multiple passes may slow down the R2R fabrication process.

Figure 6. Effect of spray passes: SEM images of the (a) PEDOT:PSS and (b) PEDOT:PSS + P3HT:PCBT layers for initial solution concentration of $c_{0}=5 \mathrm{~g} / \mathrm{L}$ and substrate speed of $0.6 \mathrm{~m} / \mathrm{s}$. The left column shows samples prepared in a single pass, and the right column in a double pass.
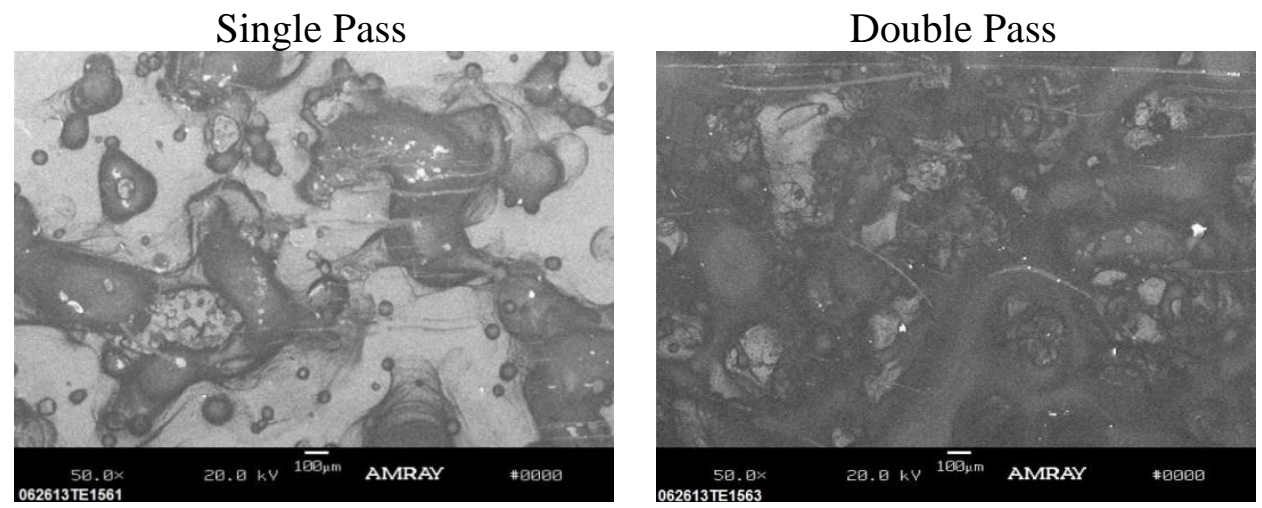

(a) PEDOT:PSS at $c_{0}=5 \mathrm{~g} / \mathrm{L}$

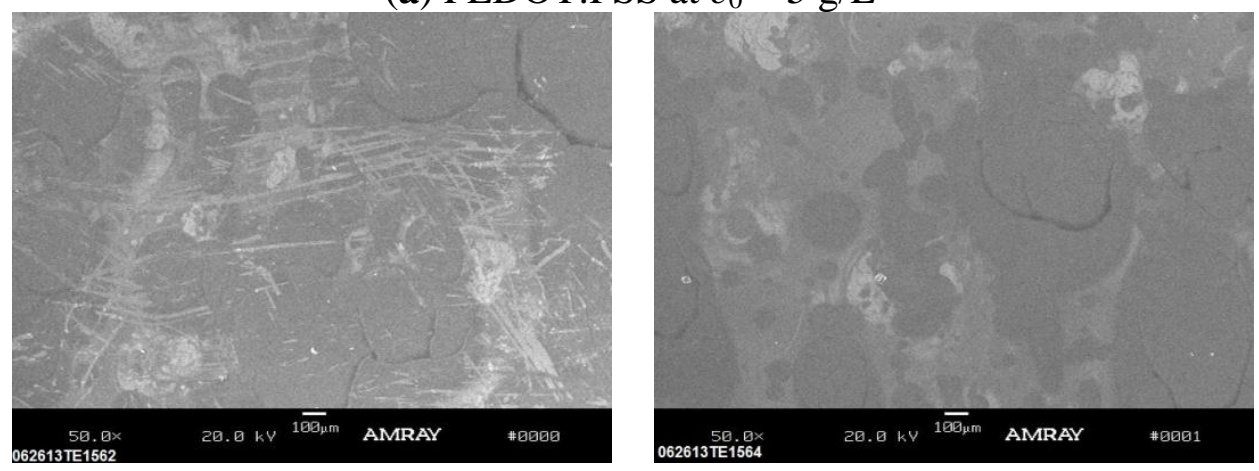

(b) PEDOT:PSS + P3HT:PCBM at $c_{0}=5 \mathrm{~g} / \mathrm{L}$

Once the SEM surface images were obtained, the samples were cut from the middle part and the cross sectional images were obtained and analyzed. The cutting process might have altered the film by imposing a force on its surface. What is observed in all cross sectional images is the formation of a rather uniform film with a thickness of few micrometers. In some cases, larger piles or splats are also visible. Figure 7 shows two typical cross sectional images of PEDOT:PSS and PEDOT:PSS + PCBM:P3HT layers both using double spray passes. The images show a uniform film for PEDOT:PSS and a less uniform film for the stacked layers of PEDOT:PSS + P3HT:PCBM. With the help of the scale bar, it is deduced that the PEDOT:PSS film thickness is about $4 \mu \mathrm{m}$ and that of the PEDOT:PSS + P3HT:PCBM is about $8 \mu \mathrm{m}$. Note that the film in Figure $7 \mathrm{a}$ is comprised of 2 passes and in $7 \mathrm{~b}$ four passes (two passes of each solution), where the distinct passes is discernible in the former and not discernible in the latter.

Film thickness is an important parameter that may affect the cell performance through exciton diffusion, charge separation and electron and hole transfer and also materials consumption. Film 
thickness is mainly affected by parameters such as precursor and carrier gas flow rate, solute concentration, nozzle-substrate spacing, etc. A decrease in the solute concentration results in a decrease in film thickness. The initial concentration of the solution can be used to calculate the amount of nonvolatile solid content available in the spray (e.g., PEDOT:PSS or P3HT-PCBM). Eventually, and after complete evaporation of the solvent, this solid content is spread on the surface. The average film thickness can be obtained from the information of the wetted spray area on the substrate, the substrate speed and the solid content density. In Ref. [5] we derived an equation for the film thickness based on the average droplet size, but the following mass balance equation seems more realistic and is recommended:

$$
\lambda=\frac{q c_{0} / \rho_{s}}{w u_{\text {sub }}}
$$

where $\lambda$ is the film thickness, $c_{0}$ is the initial solution concentration, $q$ is the precursor flow rate, $\rho_{s}$ is the density of the solid content, $w$ is the diameter or width of the spray pattern on the substrate, and $u_{\text {sub }}$ is the substrate speed. The numerator of Equation (1) is the rate of solute mass delivered to the substrate, and the denominator is the substrate swept or coated area by the nozzle. In the derivation of Equation (1), the effect of porosity is neglected. The presence of porosity can increase the film thickness.

Figure 7. Typical images of the samples cross sections; (a) PEDOT:PSS layer at $c_{0}=5 \mathrm{~g} / \mathrm{L}$, $u_{\text {sub }}=0.6 \mathrm{~m} / \mathrm{s}$ and number of passes $=2$; (b) PEDOT:PSS + PCBM:P3HT layers at $c_{0}=5 \mathrm{~g} / \mathrm{L}, u_{\text {sub }}=0.3 \mathrm{~m} / \mathrm{s}$ and number of passes $=2$.

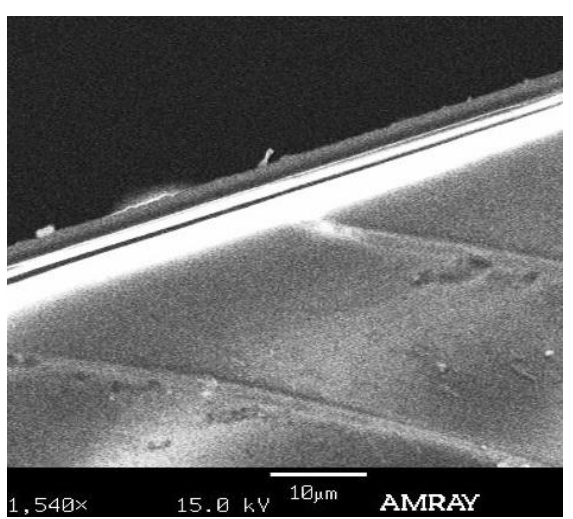

(a)

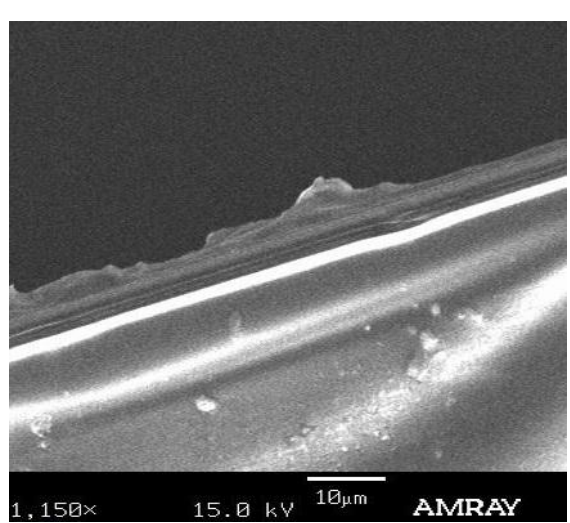

(b)

Figure 8 displays the measured (SEM and optical profilometry) and estimated film thicknesses using Equation (1) versus precursor concentration for two-pass spray coated PEDOT:PSS layer at two substrate speeds. The standard deviation of the optical profilometry experimental data is shown as error bars. Both experimental data and the theoretical estimations predict an increase in the film thickness with an increase in the precursor concentration. However, while the theory predicts a linear increase in thickness with concentration, the experimental data show that the curve tends to level off indicating that the film is more porous when solution concentration is lower, which is physically reasonable (note that the thickness is shown in the logarithmic scale). The SEM measurements show a larger film thickness than those shown by the optical profilometry measurements; the theoretical estimations are in between. Given that Equation (1) neglects the porosity, the SEM estimation of the film thickness seems to be closer to the actual thickness indicating the inadequacy of optical profilometry for non-uniform films. 
Based on the above results, it seems that the using a higher spray flow rate than that used in this study $(10 \mathrm{~mL} / \mathrm{min})$ and a lower impact air flow rate would improve the coating process and the integrity of the film. A lower substrate speed also leads to the formation of a smoother film, although it slows down the fabrication process. It seems that the high impact air pressure used in this study created a sporadic finish on the substrate. The droplets generated by our ultrasonic nozzle are $48 \mu \mathrm{m}$ and therefore rather large. Using an ultrasonic nozzle that generates smaller droplets may be beneficial as well. Also, a lower substrate temperature and lower surface tension solution that would delay the solvent evaporation rate and allow for droplet spreading and merging on the substrate would be beneficial to the formation of a smooth thin film. The findings of this paper can yield an improved process in the future to obtain more desirable films.

Figure 8. Measured and estimated film thickness versus precursor concentration for two-pass spray-coated PEDOT:PSS layer: (a) substrate speed $0.3 \mathrm{~m} / \mathrm{s}$ and (b) substrate speed $0.6 \mathrm{~m} / \mathrm{s}$.

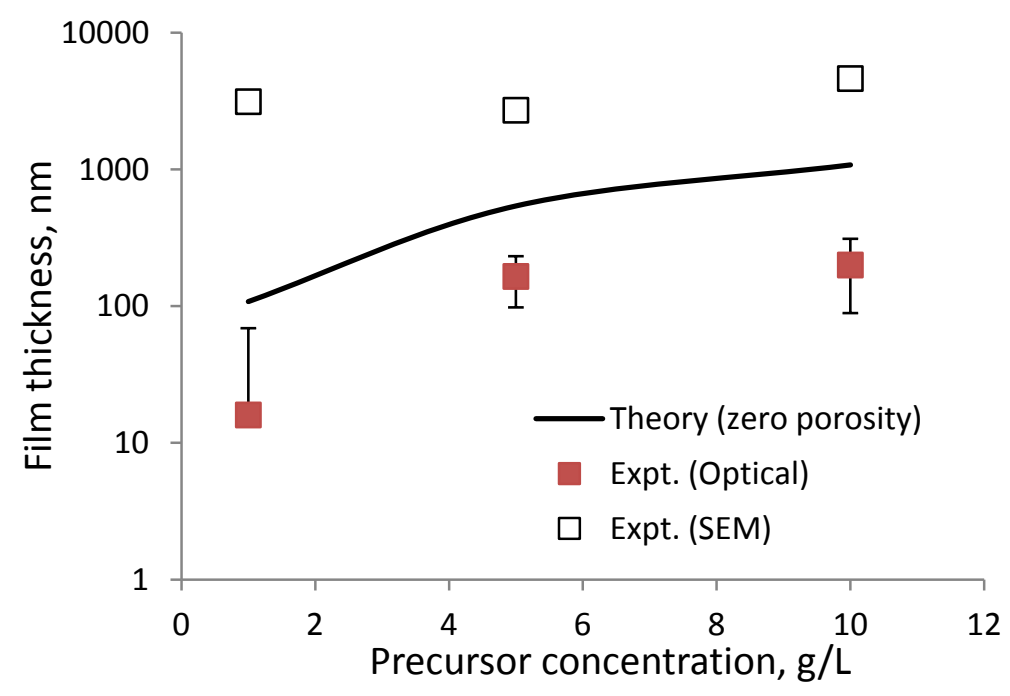

(a)

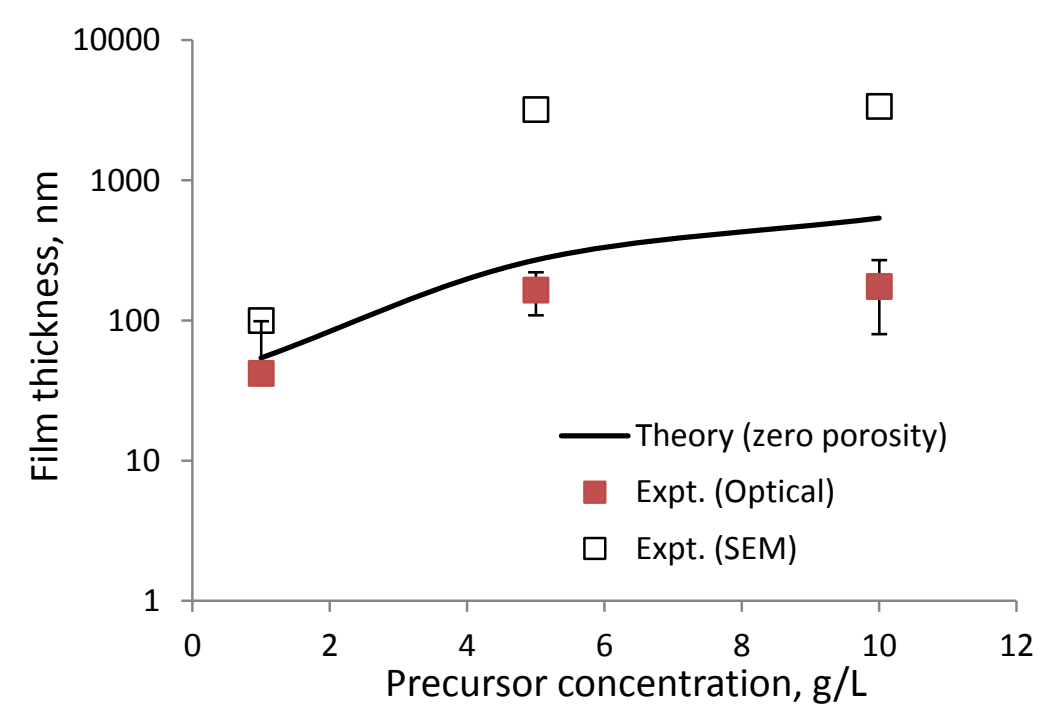

(b) 


\section{Conclusions}

Ultrasonic atomization was used to fabricate PEDOT:PSS electron-blocking layer and P3HT:PCBM active layer stacked on PEDOT:PSS. The film morphology and topography analysis using SEM and optical profilometry showed that the films are comprised of a thin layer which is rather uniform and some coins or splats on the top. It was found that the application of multiple spray passes results in the formation of more uniform films. A precursor solution concentration of $5 \mathrm{~g} / \mathrm{L}$ was found to be better than 1 or $10 \mathrm{~g} / \mathrm{L}$, as far as the fabrication of uniform films with moderate thickness is concerned. However, the results showed that using a low concentration solution with few passes results in the formation of sporadic layers. At low solution concentrations, using multiple layers could improve the uniformity while the thickness is still low. Also, it is concluded that a lower substrate temperature and lower surface tension solution that would delay the solvent evaporation rate and allow for droplet spreading and merging on the substrate would be beneficial to the formation of a smooth thin film.

The measured film thickness data obtained from optical profilometry and SEM cross sectional images were compared with the theoretical estimations. The agreement between theory and the two experimental methods is only qualitative, indicating the inadequacy of these surface analysis techniques for spray-on thin film characterization. Overall, while spray coating is a viable technique for the fabrication of a wide range of thin film solar cells, controlled fabrication of uniform thin films is still challenging.

\section{Conflicts of Interest}

The authors declare no conflict of interest.

\section{References}

1. Krebs, F.C. Fabrication and processing of polymer solar cells: A review of printing and coating techniques. Sol. Energy Mater. Sol. Cells 2009, 93, 394-412.

2. Søndergaard, R.R.; Hosel, M.; Krebs, F.C. Roll-to-roll fabrication of large area functional organic materials. J. Polym. Sci. Part B Polym. Phys. 2013, 51, 16-34.

3. Wengeler, L.; Schmitt, M.; Peters, K.; Scharfer, P.; Schabel, W. Comparison of large scale coating techniques for organic and hybrid films in polymer based solar cells. Chem. Eng. Process. 2013, 68, $38-44$.

4. Galagan, Y.; Coenen, E.W.C.; Sabik, S.; Gorter, H.H.; Barink, M.; Veenstra, S.C.; Kroon, J.M.; Andriessen, R.; Blom, P.W.M. Evaluation of ink-jet printed current collecting grids and busbars for ITO-free organic solar cells. Sol. Energy Mater. Sol. Cells 2012, 104, 32-38.

5. Eslamian, M. A model for the fabrication of polymer solar cells by spray coating. Dry. Technol. 2013, 31, 405-413.

6. Krebs, F.C. Polymeric Solar Cells; DEStech Publications, Inc.: Lancaster, PA, USA, 2010.

7. Institut für Thermische Verfahrenstechnik, Germany. Available online: https://www.tvt.kit.edu/ 504_1073.php (accessed on 16 January 2014).

8. Chilvery, A.K.; Batra, A.K.; Guggilla, P.; Lal, R.B.; Surabhi, R. A versatile technique for the fabrication of PEDOT: PSS films for organic solar cells. Energy Sci. Technol. 2012, 4, 6-11. 
9. Kim, K.-J.; Kim, Y.-S.; Kang, W.-S.; Kang, B.-H.; Yeom, S.-H.; Kim, D.-E.; Kim, J.-H.; Kang, S.-W. Inspection of substrate-heated modified PEDOT:PSS morphology for all spray deposited organic photovoltaics. Sol. Energy Mater. Sol. Cells 2010, 94, 1303-1306.

10. Weickert, J.; Sun, H.; Palumbiny, C.; Hesse, H.C.; Schmidt-Mende, L. Spray-deposited PEDOT:PSS for inverted organic solar cells. Sol. Energy Mater. Sol. Cells 2010, 94, 2371-2374.

11. Steirer, K.X.; Berry, J.J.; Reese, M.O.; van Hest, M.F.A.M.; Miedaner, A.; Liberatore, M.W.; Collins, R.T.; Ginley, D.S. Ultrasonically sprayed and inkjet printed thin film electrodes for organic solar cells. Thin Solid Films 2009, 517, 2781-2786.

12. Lee, J-H.; Sagawa, T.; Yoshikawa, S. Morphological and topographical characterizations in spray coated organic solar cells using an additional solvent spray deposition. Org. Electron. 2011, 12, 2165-2173.

13. Lee, J-H.; Sagawa, T.; Yoshikawa, S. Thickness dependence of photovoltaic performance of additional spray coated solar cells. Thin Solid Films 2013, 529, 464-469.

14. Lewis, J.E.; Lafalce, E.; Toglia, P.; Jiang, X. Over $30 \%$ transparency large area inverted organic solar array by spray. Sol. Energy Mater. Sol. Cells 2011, 95, 2816-2822.

15. Girotto, C.; Moia1, D.; Rand, B.P.; Aernouts, T.; Heremans, P. Efficient Polymer Solar Cells via an All-Spray-Coated Deposition. In Proceedings of the 35th IEEE Photovoltaic Specialists Conference (PVSC), Honolulu, HI, USA, 20-25 June 2010; pp. 001068-001072.

16. Girotto, C.; Moia, D.; Rand, B.P.; Heremans, P. High-performance organic solar cells with spray-coated hole-transport and active layers. Adv. Funct. Mater. 2011, 21, 64-72.

17. Girotto, C.; Rand, B.P.; Genoe, J.; Heremans, P. Exploring spray coating as a deposition technique for the fabrication of solution-processed solar cells. Sol. Energy Mater. Sol. Cells 2009, 93, 454-458.

18. Tait, J.G.; Rand, B.P.; Heremans, P. Concurrently pumped ultrasonic spray coating for donor:acceptor and thickness optimization of organic solar cells. Org. Electron. 2013, 14, 1002-1008.

19. Chen, L.-M.; Hong, Z.; Kwan, W.L.; Lu, C.-H. ; Lai, Y.-F.; Lei, B.; Liu, C.-P.; Yang, Y. Multi-source/component spray coating for polymer solar cells. ACS Nano 2010, 4, 4744-4752.

20. Peh, R.J.; Lu, Y.; Zhao, F.; Lee, C.-L.K.; Kwan, W.L. Vacuum-free processed transparent inverted organic solar cells with spray-coated PEDOT:PSS anode. Sol. Energy Mater. Sol. Cells 2011, 95, 3579-3584.

21. Lee, J.-H.; Sagawa, T.; Yoshikawa, S. Fast screening of the optimal polymer ratio for organic solar cells using a spray-coating deposition method for the fullerene mixture. Energy Technol. 2013, 1, 85-93.

22. Eslamian, M. Spray-on thin film PV solar cells: Advances, potentials and challenges. Coatings 2014, 4, 60-84.

(C) 2014 by the authors; licensee MDPI, Basel, Switzerland. This article is an open access article distributed under the terms and conditions of the Creative Commons Attribution license (http://creativecommons.org/licenses/by/3.0/). 